\title{
ICCA JOURNAL REFEREES IN 1997
}

\section{The Editorial Board}

The Editor-in-Chief and The Editorial Board would like to acknowledge the expert assistance of the following persons in refereeing submissions to the Journal during 1997. We hope to meet an equal willingness among the referees for the years to come.
L.V. Allis
Chr. Donninger
A. Junghanns
J. Nunn
D. Beal
R. Feldmann
H. Kaindl
A. Plaat
E. Baum
J. Fürnkranz
R.E. Korf
W. Pijls
Y. Björnsson
D. Hartmann
D.N.L. Levy
J. Schaeffer
I. Blom
A. de Bruin
R.M. Hyatt
V. Manohararajah
J.W.H.M. Uiterwijk
D. Carmel
E.A. Heinz
T.A. Marsland
A. Walker
H. Iida
M. Newborn
J.C. Weill

\section{AEGON STOPS}

ICCA Communication

by C. de Gorter ${ }^{1}$

The Hague, The Netherlands

The Board of AEGON has decided to stop funding their series of successful annual Man versus Machine tournaments. The Board's decision no longer to sponsor the tournament came as a big surprise to the organizers, the in-house helpers, the participants and the public. As reasons for stopping they mention that the tournaments did not live up to their expectations of obtaining media interest, in particular that of television and daily newspapers. Moreover, they expect that computers will soon no longer provide tough opposition for human players. Thus, they decided to cease these magnificient tournaments.

[The Editorial Board regrets this decision, but is grateful for the long-standing support which AEGON has provided over the years. Their tournaments have contributed significantly to the development of computer chess and computer-chess research. They have been landmarks which measured exactly the increase in playing strength annually. It is hoped that a successor sponsor can be found in The Netherlands or outside. - Ed.]

\section{CALENDAR OF COMPUTER-GAMES EVENTS 1998}

\section{February 11-15, 1998}

International Computer-Chess Tournament to be held in Paderborn, Germany. Details from Ulf Lorenz, Room F2.416, Fürstenallee 11, 33102 Paderborn, Germany. Email: flulo@uni-paderborn.de.

\section{June 2-7, 1998}

The First Advanced Chess Match: Garry Kasparov vs. Veselin Topalov to be held in Leon, Spain. Six games of 60 minutes per side will be played on June 3-5. Each player may use a computer. Details from Frederic Friedel, Lohmannsweg 32, D-21075 Hamburg, Germany. Email: 100066.1035@compuserve.com.

\section{August 24-30, 1998}

Minds Sport Olympiad. Details from David Levy, 89, Constantine Road, London NW3 2LP, England. Email: DavidL@intrsrch.demon.co.uk.

\section{August 28-29, 1998}

The $4^{\text {th }}$ FOST-Cup World-Open Computer-Go Championship to be held at Nihon Ki-in in Tokyo. For information: Mr. Maruyama, FOST office, 1-4-24, Hiyoshi-Honcho, Kouhoku-ku, Yokohama-shi, Kanagawa, Japan, Zip code: 223, Tel.: +81-45-562-5432, Fax: +81-45-562-6132, Email: atakahashi@koei.co.jp.

\footnotetext{
' Valkenboskade 607, 2563 JE The Hague, The Netherlands. Telephone: 070-3643729.
} 